Payne, Daniel

Suggested citation:

Payne, Daniel (2008) Exhibiting information literacy: Site-specific art and design interventions at the Ontario College of Art \& Design. Art Libraries Journal, 33 (1). pp. 3541. ISSN 0307-4722 Available at http://openresearch.ocadu.ca/id/eprint/366/

Open Research is a publicly accessible, curated repository for the preservation and dissemination of scholarly and creative output of the OCAD University community. Material in Open Research is open access and made available via the consent of the author and/or rights holder on a non-exclusive basis.

The OCAD University Library is committed to accessibility as outlined in the Ontario Human Rights Code and the Accessibility for Ontarians with Disabilities Act (AODA) and is working to improve accessibility of the Open Research Repository collection. If you require an accessible version of a repository item contact us at repository@ocadu.ca. 


\title{
Exhibiting information literacy: site-specific art and design interventions at the Ontario College of Art \& Design
}

\author{
Daniel Payne
}

\section{The Ontario College of Art \& Design is a university that provides \\ 1 undergraduate education to a markedly diverse student body. Although the} Dorothy H. Hoover Library offers proactive information literacy programming targeting academic research needs, only peripheral support was traditionally given to studio practice. To rectify this gap the reference librarians, in dialogue with selected design and art faculty, endorsed a Library exhibition program using the Library as both case study and exhibition site. An analysis of several works featured in a recent exhibition demonstrates how art can establish an eloquent dialogue with a visually-oriented learning community and lead to the examination of key philosophical and ethical issues in librarianship.

Since 1876, the Ontario College of Art \& Design (OCAD) has remained at the forefront of the Canadian art world by maintaining a stable commitment to a progressive studio-based curriculum that integrates a variety of verbal, textual and iconic instructional strategies. ${ }^{1}$ Such a constructivist approach to education accommodates a range of different learning styles, giving students the opportunity to express a unique creative voice that allows them to communicate with a wider cultural context. The following article presents an experiment in integrating studio-based practices with the information literacy program at the University's Dorothy H. Hoover Library. By mapping studio instruction practices at the University onto art exhibitions held in the Library space, faculty and librarians were able to successfully integrate their two instructional practices, while challenging students to reflect on philosophical and ethical issues currently confronting libraries.

A description of OCAD's studio-based practices which employ a three-tiered level of student and faculty engagement - helps contextualize the strategies used in this library exhibition project.
First, collaborative constructivist learning approaches are used to introduce key concepts. Instructors use a variety of tactics, ranging from lectures to showing images, to demonstrations of particular artistic techniques. Most often these teaching practices are offered in an impromptu manner directly in response to issues as they arise in the course of a class, thus adhering closely to problem-based learning techniques. As Charles Garoian comments in 'Performance art as critical pedagogy in studio art education', the studio experience becomes a form of performance art where instructors 'perform language'. In general, instructors act as facilitators who create a strong sense of community between teacher and student, ${ }^{2}$ avoiding much of the hierarchy of formal academic classroom settings.

Secondly, a process of negotiation occurs. All studio classes rely on 'one-on-one' work with instructors: students at the easel, the pottery wheel or computer monitor receive direct and often tactile instruction. These student-teacher interactions employ communication that is non-verbal, creating a learning 'ecology' where actions are as important as words. This is the process where individual 
creative vision negotiates with best practice and that which is technically feasible, as recommended by the faculty instructor.

The fundamental, final stage of studio practice is the 'critique'; no work of art or design at OCAD is complete until it has passed through the process that is at core a form of peer-review. During this procedure students exhibit or display their creations; then all involved in the artistic process collectively discuss the work, considering issues such as its relation to a larger thematic exhibition, the form of the work or technical issues such as balance, unity, composition and line. Of specific concern is the question of whether the form expresses some sort of content or cognitive idea; does the work of art or design 'speak to the viewer'. Often this process is emotionally charged: James Elkins, author of the controversial book Why art cannot be taught, likens critiques to the art of seduction where intense 'emotional outbursts' are the norm; so much so that rational discourse can be silenced. ${ }^{3}$ Despite such criticisms, critiques are vital, as this is the point where individual creativity meets public scrutiny. If the artwork is to engage with an audience, then some form of dialogue between viewer and creator must occur. Ultimately, as in the case of peer-review in the print world, the end product is the voice of not only an individual creator, but also that of a larger peer-group.

\section{Integrating studio instruction with information literacy}

In an effort to tap into this rich instructional forum, Dorothy H. Hoover Library reference librarians discussed with both art and design faculty members the launch of an exhibition program using the Library as both site and case study. The premise of this project was to use the library's daily practices, collections and guiding philosophies as the thematic subject of the exhibitions. A series of exhibitions involving Canadian photographer Vid Ingelevics's fourth year thesis class - aptly titled 'Search, research, resolution' - offers an ideal example of the creative dialogue made possible by integrating information literacy and studio-based principles. To date, three end-of-term exhibitions have been presented. At the outset, students attend a seminar in the OCAD Library, where guiding library philosophies and organizational practices are presented and, most importantly, critiqued. For example, in our most recent exhibition, potentially biased practices in the Library of Congress classification of First Nations' art were discussed. Early cataloguing practices placed books on contemporary Canadian Indigenous art in E 51 E 99, a section listed, rather archaically, as 'Indian tribes and cultures'. A lively debate ensued, with some advocating Native art as an expression of a unique indigenous cultural view since using the value-laden term 'art', as defined by Western European aesthetics, represents a form of colonialism. Others expressed the opposite: failing to acknowledge the creative output of Aboriginal creators is an overt example of discrimination. Such complex issues are not easily resolved and, from our vantage point, provide ideal subject matter for the intense reflection involved in studio-based practice.

Following this initial presentation, which uses the Library as a studio space, students present a description of their projects to OCAD reference librarians to ensure that the works do not compromise daily circulation and reference services. Some students, for example, expressed a wish to move segments of the collection or, in one instance, a young artist sought to hang life-sized paper cut-outs of people in the aisles. Either of these situations would potentially compromise access to our collections - especially for students in wheel chairs and would, in effect, demonstrate a failure to grasp the ultimate objectives of the entire exhibition project. This emulation of the negotiation process of studio practice required one-on-one, tutorial-type dialogue to mediate between our needs as librarians and those of the artistic voice.

Lastly, the final critiques are held in the Library space with the full participation of a reference librarian.

\section{Students interpret libraries through art}

A detailed analysis of several works from our most recent exhibition reveals the profound interpretations offered by these deceptively simple works. Kaitlin Chasowy explored the tension between library policies and user-centered service ethics by bombarding the OCAD Library service areas with small library catalogue-sized cards with 'Proposed new rules' (fig. 1, 1a). In all approximately 30 were posted most of which suggested rather draconian measures to guide, or perhaps dictate, user behaviour. Jauntily tacked onto the sides of computer monitors, affixed to reading carrels and group work tables, perched on display cabinets, the cards initially seem to encourage users to read and 


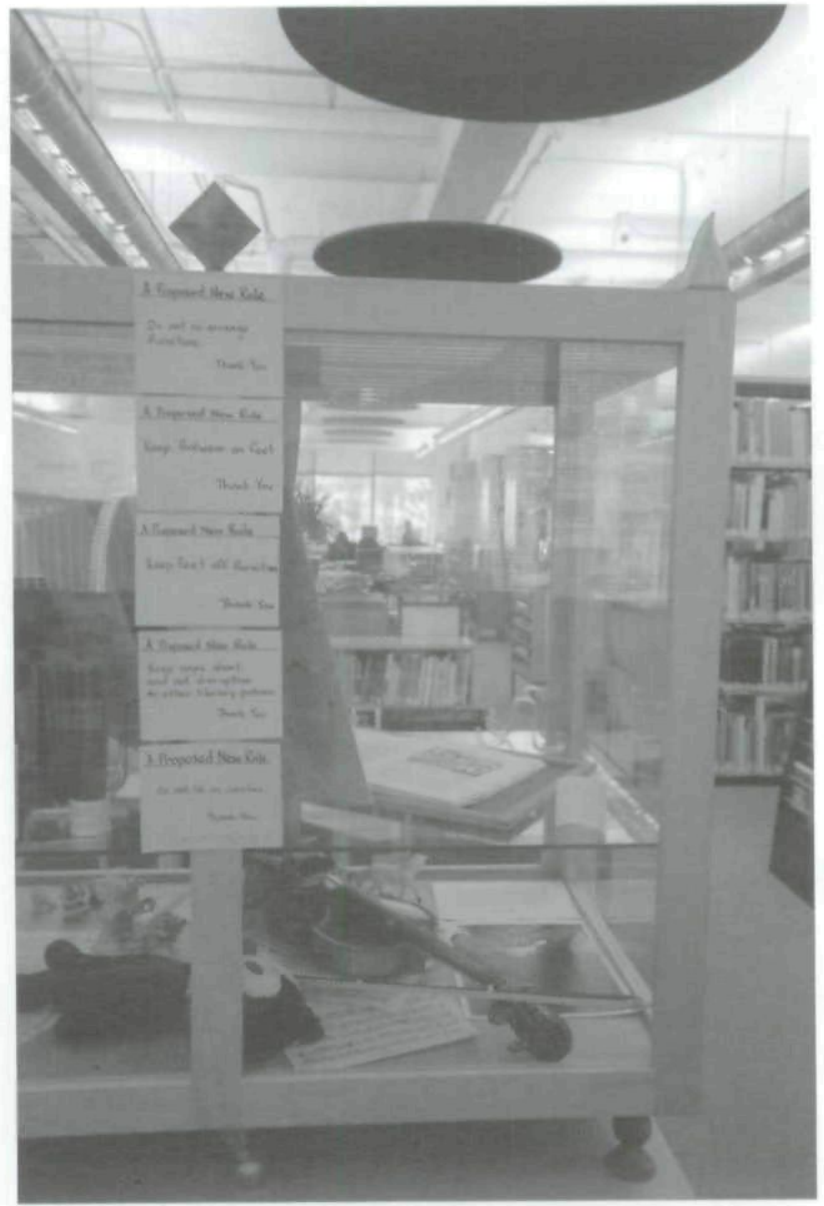

Fig. 1. Kaitlin Chasowy. Mixed media installation, Proposed new rules. Dorothy H. Hoover Library, OCAD, December 2006. Image courtesy of Lino Ragno, OCAD AV \&

Imaging Services.

talk about these new policy changes, yet the sheer number, with their repetitive bold title 'proposed new rule', soon become visually oppressive for the viewer. On a surface level, the work overtly criticizes autocratic library policies; however, it was in gauging the reaction of users that the work was fully realized. In general, a surprisingly small

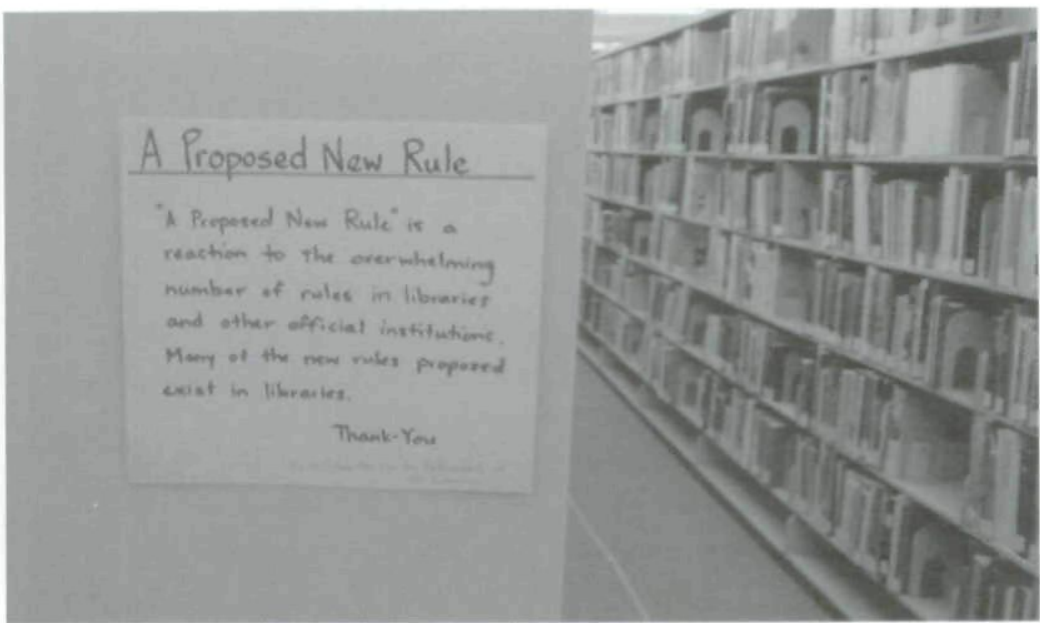

Fig. 1a. Chasowy. Proposed new rules.

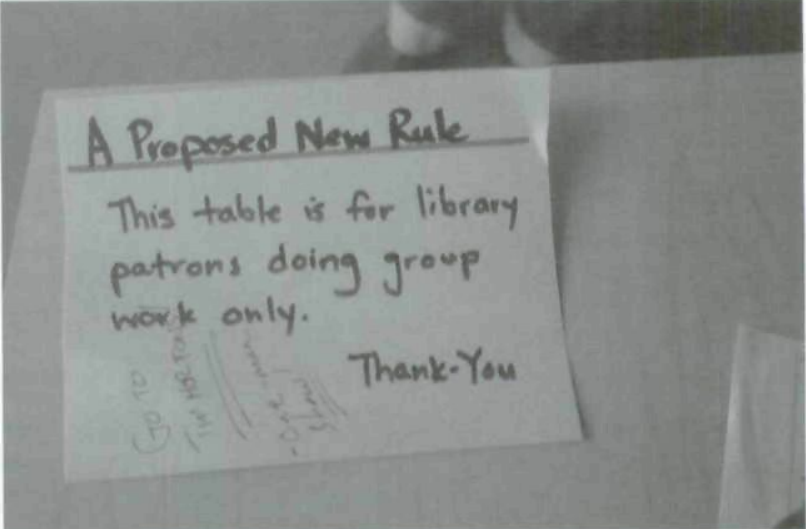

Fig. 1b. Chasowy. Proposed new rules.

number of students inquired about the cards despite the sweeping and authoritarian nature of many of the proposed policy changes, which, sadly, hints at a user population overly saturated by regulations. It is only when one of the cards directly impacted on a user in his/her research needs that the "proposed new rule' became an issue. One student, for example, after reading that a large table could only be used for group work, sheepishly asked whether he could sit and read at it, despite the fact that the Library was almost full and the 'group study' table was the last one available.

Chasowy pushes the delicate balance of our 'user friendly' ethics. In levying fines, blocking patron records, restricting food consumption or enforcing quiet areas, librarians believe they are working in the best interests of the collection, which ultimately - although they might not realize it - benefits patrons. Yet with such strict standards, can libraries truly claim to be user-centered? Do libraries in fact impose regulations on a user population that has no choice but to obey? An informative example occurred with one 'proposed rule' card affixed to a group study table, which, after several days on display, was inscribed with graffiti by a less than impressed student (fig. 1b). This offers an additional layer of meaning to the installation: when libraries use 'dictatorial' policy statements posted on signs or posters as a means of communicating, students will often respond with their own 'dictatorial' answers, in the form of graffiti or vandalism. Chasowy demonstrates that policies must be the starting point for negotiation with patrons, and be used to foster positive dialogue rather than as a forum for confrontation.

Heather Quinsey's Polaroid installation, titled 'Choose your own research', tackled complexities involved 


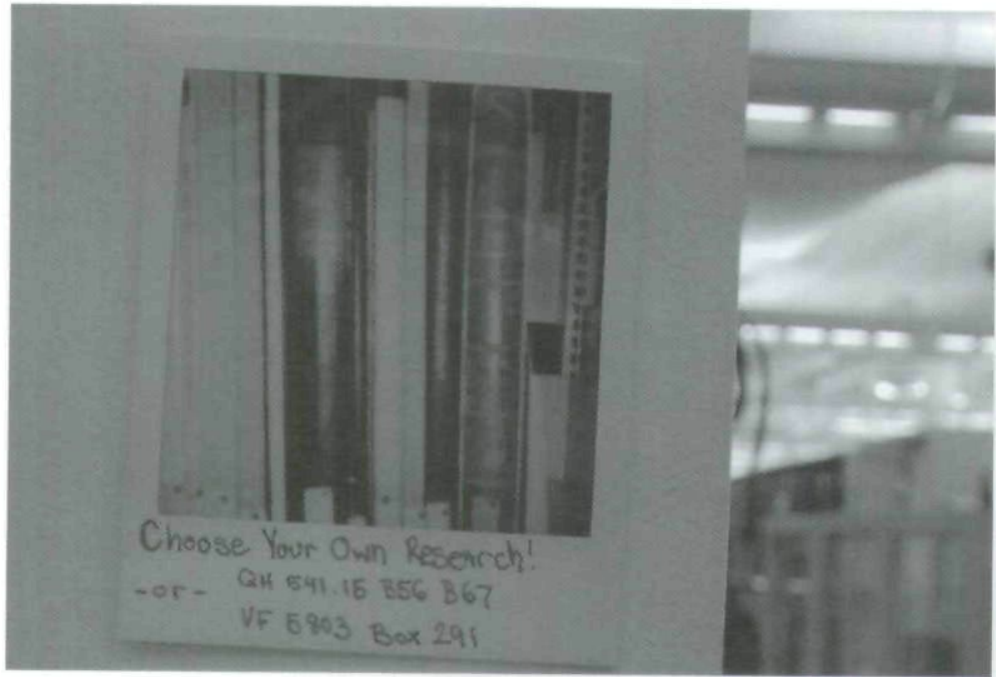

Fig. 2. Heather Quinsey. Polaroid photographic installation, Choose your own research. Dorothy H. Hoover Library, OCAD, December 2006.

Image courtesy of Lino Ragno, OCAD AV \& Imaging Services.

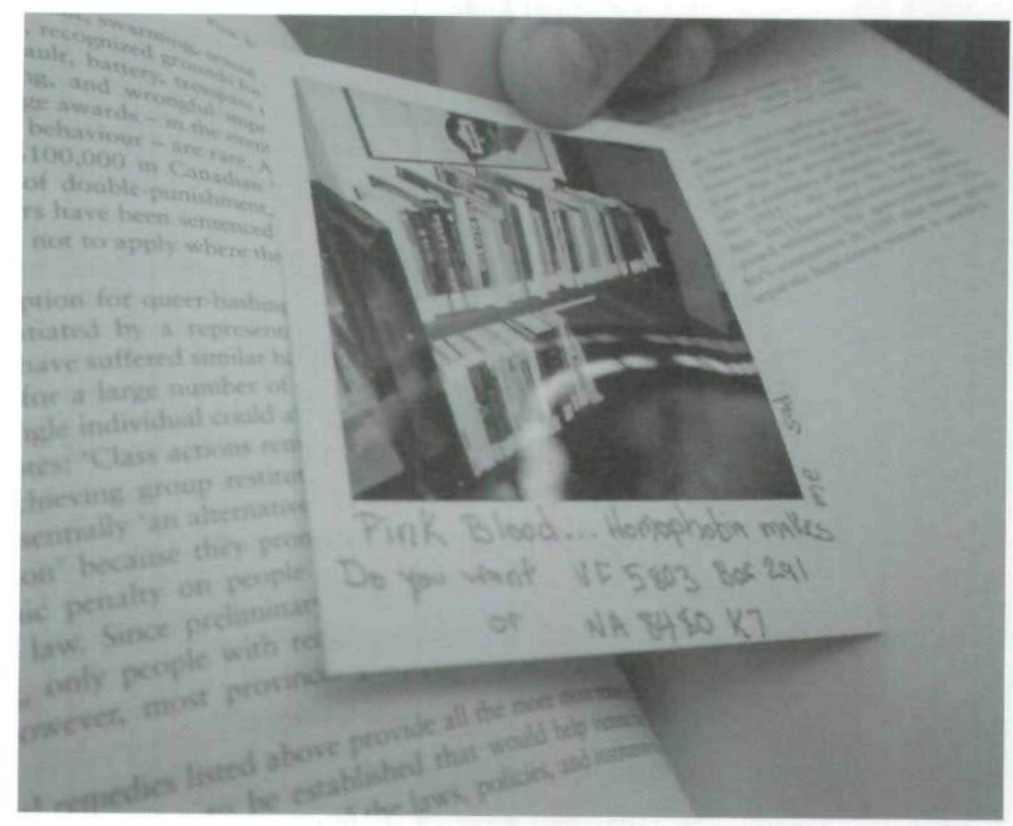

Fig. 2a. Quinsey. Choose your own research.

in researching, especially when dealing with issues of gender and sexuality. Conceived as a scavenger hunt, the project led researchers on a route of many potential paths. The installation began with a Polaroid displayed over our online library catalogue; written below the image were the call numbers without titles - to a book and an exhibition catalogue located in different sections of the Library (fig. 2). On retrieving either publication, participants discovered that the books explored aspects of sexual diversity. As well, each book retrieved offered a new Polaroid photograph hidden between the pages that cited two additional call numbers (fig. 2a). In all, several dozen photographs were dispersed throughout the collection. Quinsey's work comments on the aspect of chance in research processes, as well as highlighting how decisions can lead researchers along unexpectedly divergent lines of inquiry. The potential fragility of research strategies is also implied: if a book listed on a particular Polaroid had been signed out, or the photograph removed by another user, the thread of the scavenger hunt was irrevocably broken. Even more emphatically, the work underscores how research is a cumulative process. A student finding the Polaroid image out of context of the scavenger hunt format will not understand the meaning of the images nor the book citations Quinsey offers.

As regards subject matter, hiding photographs within the pages of books offers a forceful metaphor of how subjects of sexuality, gender identity and queer theory are 'buried' in the problematic HV section, disturbingly titled 'Social pathology, Social and public welfares, Criminology'. Similarly, one of the first publications offered by Quinsey is from our exhibition catalogue collection. Students interested in artists who present themes of gender or homosexuality in their works are unable to browse for materials on this subject as artists are perhaps unjustly - categorized by artistic medium, then by nationality. Quinsey seems to ask the question: which is more important for lesbian, gay, bisexual, transgendered or questioning artists nationality or sexuality? Library of Congress classification practices favor the former in establishing the 'aboutness' of these books, yet are these decisions discriminatory? Such issues are significant, given that browsing is a vitally important retrieval method for LGBTQ users, who are often too intimidated to ask for assistance at the reference desk. Thus, the covert nature of finding these pictures mimics the secretive ways that LGBTQ patrons search for resources in our collection. Finally, Quinsey's suggested readings, not offered by reference staff, emphasize the importance of peer reference for LGBTQ users when searching for information on themselves and their communities.

Diego Franzoni used red tape to map a research investigation using the OCAD Library collection (fig. 3). The taped line began on the floor underneath our online library catalogue and featured a red dot with a white circle placed inside it; the installation's title 'Underlining landscape' was 


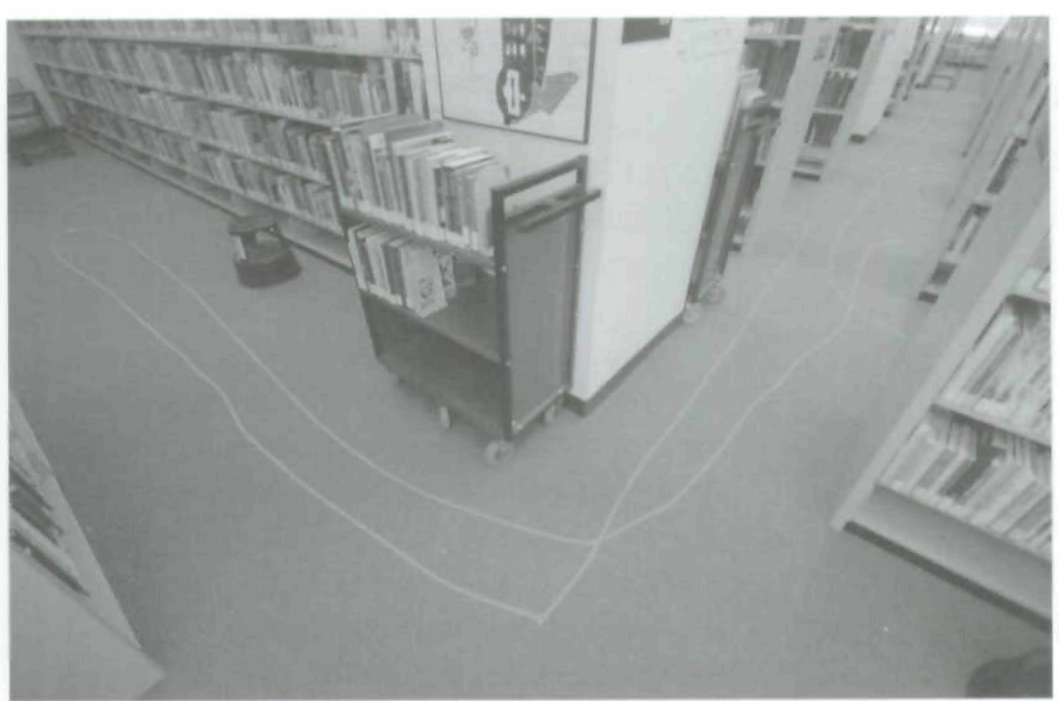

Fig. 3. Diego Franzoni. Mixed media installation, Underlining research.

Dorothy H. Hoover Library, OCAD, December 2006.

Image courtesy of Lino Ragno, OCAD AV \& Imaging Services. these key nodes, the red line was punctuated by red dots similar in size to the initial one; however, as the search progressed the interior white dots grew smaller and smaller, until the final dot - positioned under a chair at a study carrel - featured no interior white spot at all (fig. 3b, 3c).

Immediately the viewer recognizes that the white dots symbolize

Franzoni's information needs that, as they interact with the collection, are gradually satisfied despite the somewhat tangled lines on which they are placed. In general, experiencing the extent of the project, which threaded through a significant part of our Library stacks, provided viewers with a fascinating record of a unique printed on the interior circle (fig. 3a). Following the line led viewer-participants to various sections related to topics in architecture, community and social institutions, spatial theories and earth art. At

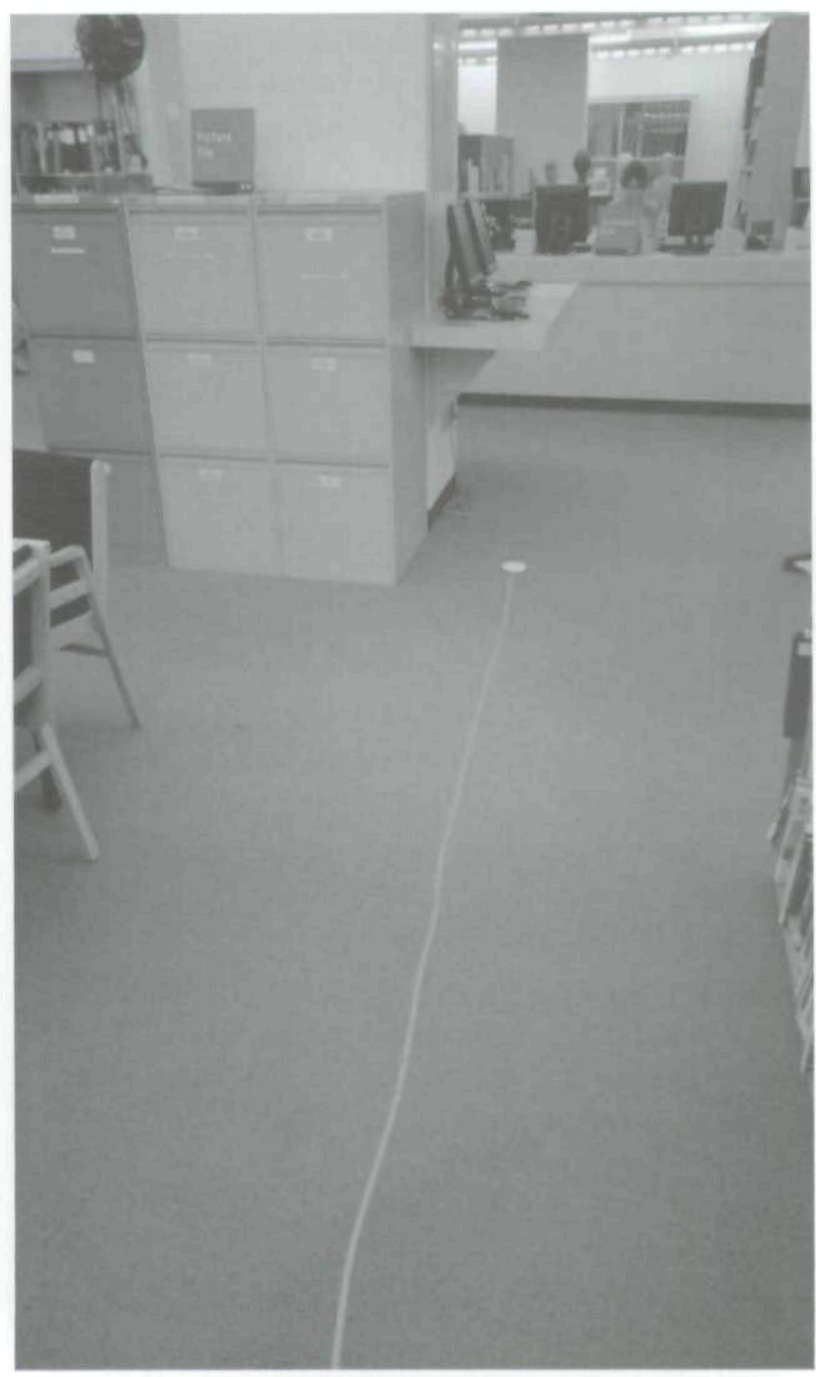

Fig. 3a. Franzoni. Underlining research. and individual search that librarians rarely view from beginning to end. A librarian may express dismay at Franzoni's rather indirect path, which, sadly, did not include the reference desk, but for him

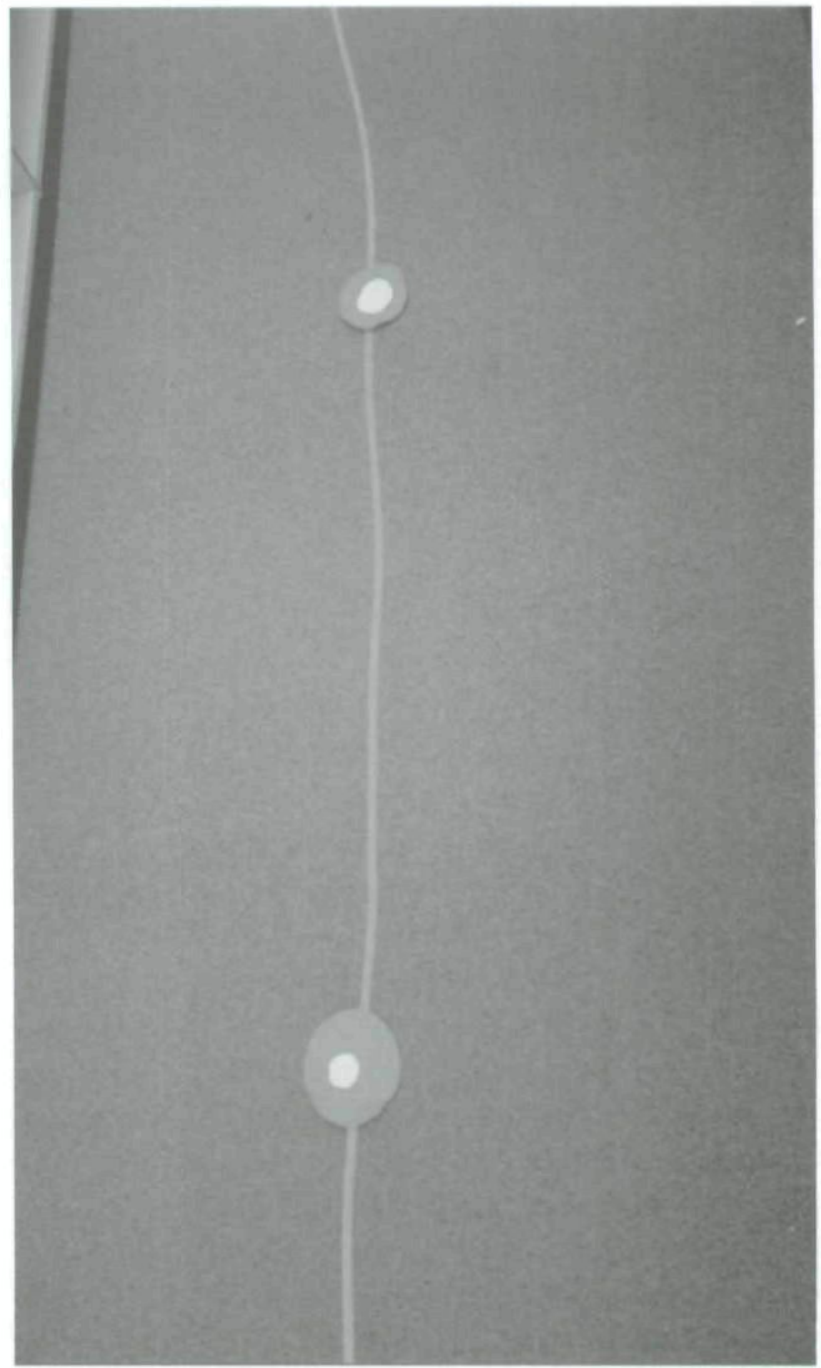

Fig. 3b. Franzoni. Underlining researcb. 


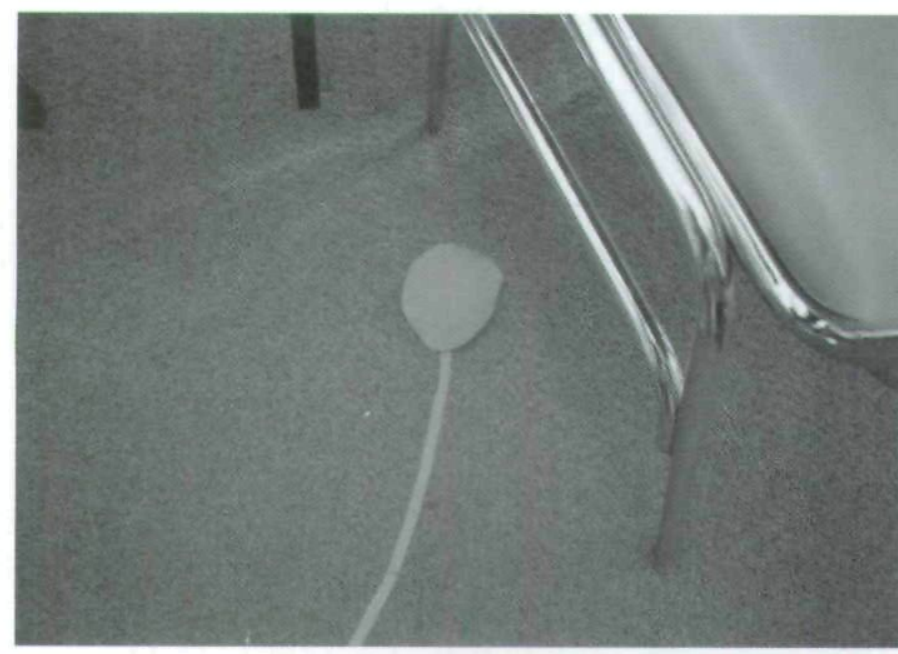

Fig. 3c. Franzoni. Underlining research.

it was a meaningful journey that, as testified by the final blank red dot, fully met his research needs. References to narrativity are unmistakable given the Aristotelian beginning, middle and end that Franzoni mapped out. The Library space, in this light, serves as a background for ephemeral human stories that weave in and out of the narratives contained in the static print/bound books on our shelves. The research-based 'plot' lines seem to embody the large-scale marginalia and aide-mémoires that one scrawls in a book, transforming the library into a metaphoric architectural text. Overall, Franzoni's installation is a reaffirmation and indeed a celebration of the physical library space. The Renaissance-like fascination with perspective is undeniable, and intentionally positions the research process as spatial and intimately linked to the bricks and mortar library.

\section{Using art to communicate information literacy}

Informal feedback from students and participating faculty indicates that the exhibition program is successful; but one must ask whether students actually learned from the process and, perhaps more importantly, if they were able to pass on this information to fellow students and viewers of the exhibition. Such a line of enquiry taps into the debate of whether art or designed objects can communicate with viewers. Although a contested subject in art history and visual culture circles, one of the most dynamic aspects of art is its open and essentially ambiguous ability to transmit ideas that cannot rely on the specificity of text-based or verbal modes of communication. The image-texts created by artist/designer elicit nebulous ideas for the viewer which often start a chain-reaction of thoughts and emotions that explore the multifaceted aspects of any given subject. Theorist Nelson Goodman suggests that such processes should not be undervalued in relation to other disciplines:

art should be taken no less seriously than the sciences as modes of discovery, creation, and enlargement of knowledge in the broad sense of advancement of ... understanding. ${ }^{4}$

Likewise, Patricia Goldblatt provides a compelling justification for viewing art and design as an effective communicative medium:
Expanded perceptions open venues for understanding and action. Attention to detail excites potential for meaning, yielding important societal insights, previously taken for granted. Transformative experiences occur when people intuit new concepts that occasion seeing in valued ways. ${ }^{5}$

In short, art is a thoroughly discursive forum, which leaves more room for play than traditional linguistic modes that actually limit the range of interpretation for an audience. ${ }^{6}$

For the Dorothy H. Hoover Library, using the reflective nature of studio-based learning has become an important new forum for us to evaluate our services, keep in open dialogue with our users and promote the idea of the Library as a place within a larger communal sphere of influences. An additional benefit has been that using studio-based instruction principles engages students on a conceptual level first, which then motivates them to explore technical searching skills as codified in the ACRL's Information literacy competency standards. ${ }^{7}$ Heather Quinsey's expert understanding of subject heading practices in 'Choose your own research' demonstrates the effectiveness of employing such open, cognitive levels of instruction to encourage students in internalizing practical searching strategies. The entire process is a reversal of our earlier procedures where seminars were given on practical usage of our Library search tools in the hope that broader philosophical or theoretical understanding would eventually emerge through using our catalogue, databases or print indexes/abstracts. For visual learners, however, this methodological reversal is critical as it mimics the collaborative environment of the studio, where broad concepts or artistic techniques are presented but are worked out technically by the students on 
their own terms, whether at the easel, the computer screen or a woodworking bench. Artists and designers need to negotiate concepts individually with their own creative voice before they are able to integrate them into their own cognitive landscapes. Ultimately, as a user-centered facility that responds directly to our institution's course structures, the exhibitions help us engage with students, using a curricular language that they understand.

Revised version of paper presented at the Art Libraries Section Open Session at the IFLA conference in Durban, South Africa, in August 2007.

\section{References}

1. Notable graduates and faculty members at OCAD include members of the Group of Seven (Arthur Lismer, A. J. Casson, Franklin Carmichael and J. E. H. MacDonald) and the Painters Eleven (Jock Macdonald, Jack Bush, William Ronald and Harold Town). See www.ocad.ca/about_ocad/faculty.htm for information on the current faculty. In 2002, OCAD received 'degree-granting status' and now is considered an art- and design-based university.

2. Charles R. Garoian, 'Performance art as critical pedagogy in studio art education,' Art journal 58, no. 1 (Spring 1999): 57-62.

3. James Elkins, Why art cannot be taugbt: a bandbook for art students (Urbana: University of Illinois Press, 2001), 132.

4. Nelson Goodman, Languages of art (Indianapolis: Bobbs-Merrill, 1968), 102.

5. Patricia F. Goldblatt, 'How John Dewey's theories underpin art and art education,' Education and culture 22, no. 1 (2006): 17.

6. Michael Ann Holly, 'Art theory,' in The Johns Hopkins guide to literary theory and criticism, ed. Michael Groden, Martin Kreiswith and Imre Szeman, 2nd ed. (Baltimore: Johns Hopkins University Press, 2005), http://litguide.press.jhu.edu/.

7. Association of Colleges and Research Libraries, 'Information literacy competency standards for higher education,' American Library Association, 2000, revised May 2007, http://www.ala.org/ala/acrl/acrlstandards/ informationliteracycompetency.cfm/.
Daniel Payne

Head, Reference, Information \& Access Services

Dorotby H. Hoover Library

Ontario College of Art \& Design

100 McCaul Street

Toronto

Canada MST 1W1

Email:dpayne@ocad.ca 
Copyright of Art Libraries Journal is the property of ARLIS-UK \& Ireland and its content may not be copied or emailed to multiple sites or posted to a listserv without the copyright holder's express written permission. However, users may print, download, or email articles for individual use. 